\title{
Development of a personal heat strain risk assessment (PHSRA) index in workplaces and its validation
}

\author{
Saeid Yazdanirad ${ }^{1}$ (D) Farideh Golbabaei ${ }^{1^{*}}$ (D), Mohammad Reza Monazzam', Habibollah Dehghan² and
} Abbas Rahimi Foroushani ${ }^{3}$

\begin{abstract}
Background: There is not a comprehensive heat stress index to screen the people susceptible to heat disorders and illnesses in hot workplaces. The present study was aimed to develop a personal heat strain risk assessment (PHSRA) index in workplaces and validate it.

Methods: This cross-sectional study was carried out on 201 Iranian male employees under various thermal conditions. At first, the demographical data of participants were gathered. After that, the heart rate and tympanic temperature of the subjects were carefully measured at times of 30,60, and 90 min of starting the work. Environmental factors were measured simultaneously. The metabolism rate and insulation value of clothes were also estimated. At the end, a novel index of the heat strain was developed using structural equation modeling in AMOS and validated using linear regression analysis in SPSS.

Results: Indirect effect coefficients of personal factors including age, body mass index, maximum aerobic capacity, and body surface area were equal to $0.031,0.145,-0.064$, and 0.106 , respectively. The coefficients of main factors including dry temperature, wet temperature, globe temperature, wind speed, metabolism, and clothing thermal insulation were obtained as $0.739,0.688,0.765,0.245,0.482$, and 0.383 , respectively. These coefficients and normalized values of the factors were used to develop a novel index. The total score of the index was categorized into four levels by optimal cut-off points of $12.93,16.48$, and 18.87. Based on the results of regression analysis, this index justifies $77 \%$ of the tympanic temperature as a dependent variable $\left(R^{2}=0.77\right)$.
\end{abstract}

Conclusions: In general, the results indicated that the novel index developed by the personal and main factors had proper validity in the prediction of thermal strain.

Keywords: Heat stress, Risk assessment, Personal factors, Main factors

\section{Background}

Approximately one-third of the world's population is frequently exposed to inappropriate climatic conditions [1]. Heat threats the human health in workplaces, particularly. The thermal exposure causes

\footnotetext{
* Correspondence: fgolbabaei@tums.ac.ir

'Department of Occupational Health Engineering, School of Public Health, Tehran University of Medical Sciences, Tehran, Iran

Full list of author information is available at the end of the article
}

severe illnesses in addition to milder disorders such as heat rash, heat cramps, heat exhaustion, and heat syncope. Heat stress can be associated with fatal outcomes if it is sustained [2]. As well as, the studies found that there are significant relationships between heat exposure and psychological, safety, socioeconomics, and productivity consequences [3]. Ramsey et al. [4] reported that workplace thermal conditions had a significant effect on the safety-related behavior

(c) The Author(s). 2020 Open Access This article is licensed under a Creative Commons Attribution 4.0 International License, which permits use, sharing, adaptation, distribution and reproduction in any medium or format, as long as you give appropriate credit to the original author(s) and the source, provide a link to the Creative Commons licence, and indicate if changes were made. The images or other third party material in this article are included in the article's Creative Commons licence, unless indicated otherwise in a credit line to the material. If material is not included in the article's Creative Commons licence and your intended use is not permitted by statutory regulation or exceeds the permitted use, you will need to obtain permission directly from the copyright holder. To view a copy of this licence, visit http://creativecommons.org/licenses/by/4.0/ The Creative Commons Public Domain Dedication waiver (http://creativecommons.org/publicdomain/zero/1.0/) applies to the data made available in this article, unless otherwise stated in a credit line to the data. 
of workers and increased the risk of accidents. Kjellstrom et al. [5] concluded that heat stress could decrease work performance and potentially generate enormous economic consequences. Tawatsupa et al. [6] concluded that heat stress might indirectly cause psychological distress because of decreased productivity, reduced income, and disrupted social activity. Various factors can be effective in producing excessive thermal strain. Intense physical activity increases heat production, and warm climatic conditions or clothing ensembles decrease heat loss during the work [7]. The main factors consist of four climatic (dry temperature, radiant temperature, humidity rate, and air movement (and two non-climatic)clothing and physical workload(variables [8]. However, there are other factors to determine the personal difference in the occurrence of heat-related disorders and illnesses. Some of them include age, obesity, aerobic capacity, and body surface area. The results of a review study conducted by Kenny et al. [9] showed that the subjects aged 60 and more had higher rates of illness, injury, and death in warm environments. Yazdanirad et al. [10] concluded that the mean heart rate of the subjects with overweight and obesity (BMI $>25 \mathrm{~kg} / \mathrm{m}^{2}$ ) was significantly higher than that of the subjects with normal weight $\left(B M I<25 \mathrm{~kg} / \mathrm{m}^{2}\right)$. Hansen et al. [11] also found that some genetic and physiological factors could reduce the human body resistance, making the subjects susceptible to heat disorders and illnesses. The results of a study carried out by Merry et al. [12] indicated that aerobic fitness attenuated the physiological effects during the exercise under warm and humid conditions. Coso et al. [13] have shown that body mass and body surface area have a negative relationship with core temperature. Havenith et al. [14] concluded that there were significant positive correlations between body surface area per mass and core temperature in warm-humid, mild, and hot-dry environments. These properties affect the thermal strain in various people. However, known heat stress indices such as wet bulb global temperature (WBGT) and predicted heat strain (PHS) indices do not consider them. Hence, these cannot be applied to screen people susceptible to heat disorders and illnesses. A few studies have attempted to develop a heat stress index using personal factors. Lu et al. [15] made a body characteristic index by variables of maximal oxygen uptake per body mass, body surface area per body mass, and percentage of body fat for assessing the thermal strain. Glass et al. [16] also estimated risk of heat strain by variables of age and gender in a simulation model. These indices have no considered the main factors, such as environmental parameters, in computing the risk. Therefore, the present study was aimed to develop a personal heat strain risk assessment (PHSRA) index in workplaces and validate it.

\section{Methods \\ Participants}

This cross-sectional study was carried out on 201 Iranian male employees, including 111 subjects from a steel factory as a hot-dry ambiance and 90 subjects from a petrochemical factory as a hot-humid environment. At first, the various parts of the above industries were carefully visited, and desired duties were selected. After that, the characterization of 400 individuals employed in these duties, including age, weight, height, and history of diseases, was extracted from their medical records. Based on this information and criteria, 199 persons were excluded, and 201 subjects were entered into the study. So that extensive ranges of variables values were involved. Inclusion criteria included the absence of mental, infectious, pulmonary, cardiovascular, renal, and digestive diseases, and lack of diabetes, hyperthyroidism, and hypertension. Other criteria were non-consumption of medications influencing on heart rate and blood pressure, and non-consumption of coffee, caffeine, and alcohol from $12 \mathrm{~h}$ before the research. Moreover, their tympanic membrane and auditory canal were examined. Exclusion criteria also consisted of noncooperation in precise measurement of physiological parameters, feeling of fatigue, heart rate over maximum permissible value computed by eq. 1 , and body temperature above $39^{\circ} \mathrm{C}$.

$$
\operatorname{HRmax}(\text { beat } / \min )=[208-(0.7 \times \text { age }(\text { year }))]
$$

\section{Sample size calculation}

The present study was aimed to develop a novel index using factors affecting body temperature. The minimum probable correlation between the novel index and body temperature was considered by 0.2 , the sample size with a confidence level of $95 \%$ and a test power of $80 \%$ was determined as follow [17]:

$$
n=\frac{\left(Z_{1-\frac{\alpha}{2}}+Z_{1-\beta}\right)^{2}}{w^{2}}+3 \cong 194
$$

Where $Z_{1-\frac{\alpha}{2}}$ is equal to 1.96 based on a confidence level of $95 \%, Z_{1-\beta}$ is equal to 0.84 based on a test power of $80 \%$, and $\mathrm{W}$ is equal to 0.203 based on a minimum correlation coefficient of 0.2 . These values were extracted from related tables [17].

Therefore, the sample size in the present study was suggested to be more than 194 subjects. 


\section{Study design and setting}

Data were collected between April and September 2019. At first, the participants were asked to sign the consent form. Later, demographical data of them, including age, height, weight, job, physical activity, and work experience, were gathered. After that, the subjects were invited to rest on a bed in a quiet and temperate room for 30 min. Their heart rate and tympanic temperature were appropriately monitored at times of 20,25 , and $30 \mathrm{~min}$ based on the standard of ISO 9886 [18]. At the next step, heart rate and tympanic temperature of the subjects were carefully measured at times of 30,60 , and 90 min of starting the work. Environmental factors including dry temperature $\left(\mathrm{T}_{\mathrm{a}}\right)$, wet temperature $\left(\mathrm{T}_{\mathrm{w}}\right)$, globe temperature $\left(\mathrm{T}_{\mathrm{g}}\right)$, and wind speed $\left(\mathrm{V}_{\mathrm{a}}\right)$ were simultaneously measured based on standards of ISO 7243 [19] and ISO 7726 [20]. The metabolism rate was estimated by the standard of ISO 8996 [21] and corrected by the standard of ISO 7243 [19]. The insulation value of clothes $\left(\mathrm{I}_{\mathrm{c}}\right)$ was also determined using the standard of ISO 9920 [22]. After ending the measuring process, values of the body mass index (BMI) $\left(\mathrm{kg} / \mathrm{m}^{2}\right)$, maximum aerobic capacity (VO2max) $(\mathrm{ml} /(\mathrm{kg} \cdot \mathrm{min}))$, and body surface area (BSA) $\left(\mathrm{cm}^{2}\right)$ were calculated by eqs. 3,4 , and 5 , respectively.

$$
B M I=\left(\frac{W_{b}}{H^{2}}\right)
$$

Where $\mathrm{W}_{\mathrm{b}}$ is body weight $(\mathrm{kg})$, and $\mathrm{H}$ is body height (m) [23].

$$
V O 2 \max =15 \times\left(\frac{\text { HRmax }}{\text { HRrest }}\right)
$$

Where HRmax is the maximum permissible heart rate computed by eq. 1 (beat/min), and HRrest is heart rate during resting (beat/min) [24].

$$
B S A=71.3989 \times H^{0.7437} \times W_{b}^{0.4040}
$$

Where $\mathrm{H}$ is body height $(\mathrm{cm})$, and $\mathrm{W}_{\mathrm{b}}$ is body weight (kg) [25].

\section{Measurement instruments}

The tympanic temperature was measured using the thermometer of Braun IRT 6530 with an accuracy of 0.1 degrees centigrade. This device, with pre-warmed tips and an exact positioning system, has been registered as a patent. Navarro et al. [26] resulted that Braun thermoscan IRT 6530 accurately estimated the body temperature of subjects during exercise under warm conditions. The heart rate was measured using a pulse monitor of Beurer PM70 with an accuracy of one beat per minute. Factors of dry temperature, wet temperature, and globe temperature were also measured using WBGT meter of TES 1369B with an accuracy of 0.1 degrees centigrade. Wind speed was separately measured using TES 1340 with an accuracy of $0.01 \mathrm{~m}$ per second. To measure body height and weight, a tape meter with an accuracy of $0.01 \mathrm{~m}$ and a digital scale of Hamilton with an accuracy of $0.1 \mathrm{~kg}$ were applied, respectively.

\section{Index development}

After collecting data, the indirect effect coefficients of the factors were computed using structural equation modeling (SEM) [27]. As well as the value of each variable was normalized between 0 and 1 follow as:

$$
v(i, n)=\frac{[v(i)-v(i, 0)]}{v(i, r e f)}
$$

where $v(i, n)$ is normalized variable, $v(i, 0)$ is the minimum measured value of the variable, and $v(i, r e f)$ is the maximum measured value minus the minimum measured value of the variable.

Equation 6 was exploited to calculate the novel index.

$$
\begin{aligned}
\text { PHSRA } & =\left[\left(C_{1} \times A_{n}\right)+\left(C_{2} \times B M I_{n}\right)+\left(C_{3} \times V O_{2 n} \max \right)\right. \\
& +\left(C_{4} \times B S A_{n}\right)+\left(C_{5} \times T_{a n}\right)+\left(C_{6} \times T_{w n}\right)+\left(C_{7} \times T_{g n}\right) \\
& \left.+\left(C_{8} \times V_{a n}\right)+\left(C_{9} \times M_{t n}\right)+\left(C_{10} \times I_{c n}\right)\right]
\end{aligned}
$$

Where $C_{1}$ to $C_{10}$ are indirect effect coefficients, $\mathrm{A}_{\mathrm{n}}$ is normalized age, $\mathrm{BMI}_{\mathrm{n}}$ is normalized body mass index, $\mathrm{VO}_{2 \mathrm{n}}$ max is normalized maximum aerobic capacity, $\mathrm{BSA}_{\mathrm{n}}$ is normalized body surface area, $\mathrm{T}_{\mathrm{an}}$ is normalized dry temperature, $T_{w n}$ is normalized wet temperature, $\mathrm{T}_{\mathrm{gn}}$ is normalized globe temperature, $\mathrm{V}_{\mathrm{an}}$ is normalized wind speed, $M_{t n}$ is normalized total metabolism, and $I_{c n}$ is normalized insulation of clothes.

\section{Statistical analyses}

Data were entered into the statistical package for the social sciences (SPSS) version 18 [28]. Skew and kurtosis curves were used to examine the normality of variables. The results showed that the statistical distribution of all factors was normal. Therefore, correlations were computed using the Pearson test. After that, a theoretical model was depicted in AMOS software [27]. The fitness of the proposed model was examined using absolute, comparative, and normed fit indices. The indirect effect coefficients of the factors were extracted from the model and used to develop the novel index. Finally, the index score was classified into four levels using Receiver operator curves (ROC) analysis. Body temperatures of 37.5, 38.0, and $38.5^{\circ} \mathrm{C}$ were considered as boundaries of risk levels [29]. Nearest points to ideal state in ROC curves 
were adopted as optimal cut-off points of the novel index. The validity of the index was also examined by linear regression analysis.

\section{Results}

This study results from a field survey involving 201 subjects, all male, where 111 were employees on a steel factory (hot-dry ambiance) and 90 on a petrochemical factory (hot-humid environment). Table 1 describes the statistical distribution of studied variables, including personal factors, main factors, and physiological parameters. The results showed that the extensive ranges of values were collected. The correlation matrix of the variables has been presented in Table 2. Of personal factors, maximum aerobic capacity had the highest correlation with tympanic temperature. Of the main factors, the most significant correlations were related to environmental variables.

Figure 1 illustrates the theoretical model analyzed by SEM. The results revealed that the main factors with a total coefficient of 0.79 and personal factors with 0.14 had a significant direct effect on the tympanic temperature. Table 3 reports the effect coefficients of the variables in producing thermal strain. Of personal factors, the body mass index and body surface area with coefficients of 0.145 and 0.106 had the highest indirect effects on the tympanic temperature, respectively. Of the main factors, the highest indirect effects belonged to environmental variables, including globe temperature with a coefficient of 0.765 , dry temperature with 0.739 , and wet temperature with 0.688 . Table 4 presents the goodness-of-fit indices of the analyzed model. Based on the results, the fitness of the model was confirmed.

PHSRA index was developed as follow:

$$
\begin{aligned}
\text { PHSRA } & =10 \times\left[0.031 \times\left(\frac{A-22.00}{33.00}\right)+0.145 \times\left(\frac{B M I-19.32}{15.62}\right)\right. \\
& -0.064 \times\left(\frac{V O 2 \max -29.30}{14.86}\right)+0.106 \times\left(\frac{B S A-1.64}{0.83}\right) \\
& +0.739 \times\left(\frac{T_{a}-21.97}{26.23}\right)+0.688 \times\left(\frac{T_{w}-12.10}{25.47}\right)+0.765 \\
& \times\left(\frac{T_{g}-23.40}{39.30}\right)+0.245 \times\left(\frac{V_{a}-0.0}{4.20}\right)+0.482 \times\left(\frac{M_{t}-130}{360}\right) \\
& \left.+0.383 \times\left(\frac{I_{c}-0.50}{0.85}\right)\right]
\end{aligned}
$$

where $\mathrm{A}$ is age (year), BMI is body mass index $(\mathrm{kg} /$ $\left.\mathrm{m}^{2}\right)$, VO2max is maximum aerobic capacity $(\mathrm{ml} /$ $(\mathrm{kg} \cdot \mathrm{min})), \mathrm{BSA}$ is body surface area $\left(\mathrm{m}^{2}\right), \mathrm{T}_{\mathrm{a}}$ is dry temperature $\left({ }^{0} \mathrm{C}\right), \mathrm{T}_{\mathrm{w}}$ is wet temperature $\left({ }^{0} \mathrm{C}\right), \mathrm{T}_{\mathrm{g}}$ is globe temperature $\left({ }^{0} \mathrm{C}\right), \mathrm{V}_{\mathrm{a}}$ is wind speed $(\mathrm{m} / \mathrm{s}), \mathrm{M}_{\mathrm{t}}$ is total metabolism (watts), and $I_{c}$ is insulation of clothes (clo). In this equation, it is important to note that signs of coefficients of body surface area and wind speed change from positive $(+0.106$ and +0.245$)$ to negative $(-0.106$ and -0.245$)$ when the dry temperature is below $35^{\circ} \mathrm{C}$ (normal skin temperature) because the heat strain decreases in these conditions.

Figure 2 exhibits the Receiver operating characteristic (ROC) curves related to various risk zones. The empirical ROC curve is a plot of the true positive rate (sensitivity) versus the false positive rate (1 specificity) for all possible cut-off values of PHSRA index, and best cut-off point has highest true posi-

\begin{tabular}{|c|c|c|c|c|}
\hline Variable & & Range & Mean & Standard deviation \\
\hline \multirow[t]{4}{*}{ Personal factors } & Age (year) & $22.00-55.00$ & 36.62 & 8.24 \\
\hline & Body mass index $\left(\mathrm{kg} / \mathrm{m}^{2}\right)$ & $19.23-34.94$ & 26.06 & 4.07 \\
\hline & Maximum aerobic capacity (ml/(kg·min)) & $29.30-44.16$ & 36.16 & 3.20 \\
\hline & Body surface area $\left(\mathrm{m}^{2}\right)$ & $1.64-2.47$ & 1.96 & 0.17 \\
\hline \multirow[t]{6}{*}{ Main factors } & Dry temperature $\left({ }^{\circ} \mathrm{C}\right)$ & $21.97-48.20$ & 24.78 & 6.01 \\
\hline & Wet temperature $\left({ }^{\circ} \mathrm{C}\right)$ & $12.10-37.57$ & 22.01 & 6.60 \\
\hline & Globe temperature $\left({ }^{\circ} \mathrm{C}\right)$ & $23.40-62.43$ & 39.89 & 9.73 \\
\hline & Wind speed (m/s) & $0.00-4.20$ & 0.58 & 0.39 \\
\hline & Total metabolism (watts) & $130.00-490.00$ & 248.47 & 103.70 \\
\hline & Clothing thermal resistance (clo) & $0.50-1.35$ & 0.83 & 0.14 \\
\hline \multirow[t]{4}{*}{ Physiological parameters } & Resting tympanic temperature $\left({ }^{\circ} \mathrm{C}\right)$ & $36.70-37.40$ & 37.01 & 0.15 \\
\hline & Working tympanic temperature $\left({ }^{\circ} \mathrm{C}\right)$ & $36.70-39.10$ & 37.70 & 0.56 \\
\hline & Resting heart rate (beat/min) & $64.00-94.00$ & 76.14 & 5.99 \\
\hline & Working heart rate (beat/min) & $70.00-189.00$ & 1.21 & 28.45 \\
\hline
\end{tabular}
tive rate and lowest false positive rate in diagnosing the intended risk level of thermal strain. In the present study, the PHSRA index was developed as an

Table 1 The statistical distribution of studied variables 
Table 2 Correlation matrix of the variables

\begin{tabular}{|c|c|c|c|c|c|c|c|c|c|c|c|}
\hline Variable & 1 & 2 & 3 & 4 & 5 & 6 & 7 & 8 & 9 & 10 & 11 \\
\hline Age & - & & & & & & & & & & \\
\hline Body mass index & $0.242^{* *}$ & - & & & & & & & & & \\
\hline Maximum aerobic capacity & $-0.515^{* *}$ & $-0.497^{* *}$ & - & & & & & & & & \\
\hline Body surface area & 0.060 & $0.817^{* *}$ & $-0.327^{* *}$ & - & & & & & & & \\
\hline Dry temperature & -0.019 & 0.093 & $-0.211^{* *}$ & 0.049 & - & & & & & & \\
\hline Wet temperature & 0.010 & -.027 & $-0.172^{*}$ & -0.065 & $0.626^{* *}$ & - & & & & & \\
\hline Globe temperature & 0.009 & 0.082 & $-0.151^{*}$ & 0.056 & $0.907^{* *}$ & $0.511^{* *}$ & - & & & & \\
\hline Wind speed & 0.014 & 0.051 & -0.107 & 0.068 & $0.296^{* *}$ & $0.152^{*}$ & $0.347^{* *}$ & - & & & \\
\hline Total metabolism & -0.026 & 0.060 & -0.085 & 0.004 & $0.318^{* *}$ & 0.131 & $0.332^{* *}$ & 0.082 & - & & \\
\hline Clothing thermal insulation & -0.102 & 0.017 & -0.036 & 0.048 & $0.454^{* *}$ & 0.054 & $0.530^{* *}$ & 0.135 & $0.321^{* *}$ & - & \\
\hline Tympanic temperature & $0.139^{*}$ & $0.177^{*}$ & $0.350^{* *}$ & 0.101 & $0.751^{* *}$ & $0.685^{* *}$ & $0.766^{* *}$ & $0.258^{* *}$ & $0.509^{* *}$ & $0.388^{* *}$ & - \\
\hline
\end{tabular}

(1) Age, (2) body mass index, (3) maximum aerobic capacity, (4) body surface area, (5) dry temperature, (6) wet temperature, (7) globe temperature, (8) wind speed, (9) total metabolism, (10) clothing thermal insulation, (11) Tympanic temperature.

${ }^{* *} P<0.01$

${ }^{*} P<0.05$

alternative to tympanic temperature in determining the risk of thermal strain. Therefore, these curves specify the optimal values of the PHSRA index equivalent to tympanic temperatures of $37.5,38.0$, and $38.5{ }^{\circ} \mathrm{C}$, as boundaries of the different risk levels. The values of all possible cut-off points of the PHSRA index with their sensitivity and specificity are reported in the tables of coordinates of ROC curves. The values of optimal cut-off points were extracted from these tables. Based on the results, the optimal cut-off points between low and moderate risk, moderate and high risk, and high and very high risk were equal to 12.93 (sensitivity $=0.953$ and specificity $=0.840$ ), 16.48 (sensitivity $=0.927$ and specificity $=0.863$ ), and 18.87 (sensitivity $=0.875$ and specificity $=0.838$ ), respectively. The area under of ROC curves (AUC) was also calculated as 0.965 (95\% CI: $0.944,0.985)(p<0.001), 0.947 \quad(95 \%$ CI: $0.919,0.976)(p<0.001)$, and 0.923 (95\% CI: 0.879 , $0.967)(p<0.001)$, respectively. Figure 3 also shows

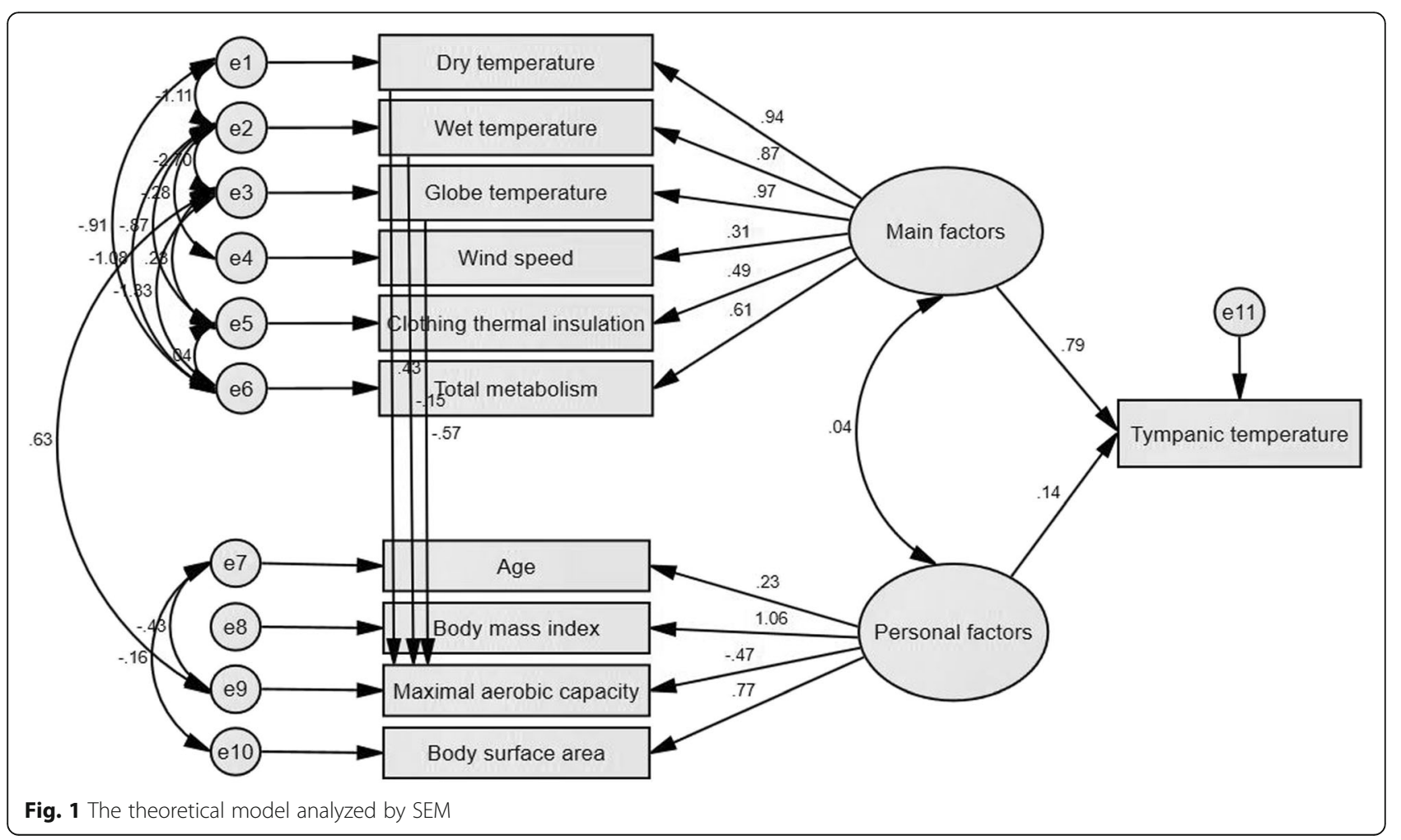


Table 3 Effect coefficients of the variables in producing thermal strain

\begin{tabular}{|c|c|c|c|c|}
\hline Variable & & Direct effect & Indirect effect & $P$ value \\
\hline \multirow[t]{5}{*}{ Personal factors } & Age & 0.226 & 0.031 & $P<0.001$ \\
\hline & Body mass index & 1.057 & 0.145 & $P<0.001$ \\
\hline & Maximum aerobic capacity & -0.466 & -0.064 & $P<0.001$ \\
\hline & Body surface area & 0.775 & 0.106 & $P<0.001$ \\
\hline & Thermal strain & 0.137 & - & $P<0.001$ \\
\hline \multirow[t]{7}{*}{ Main factors } & Dry temperature & 0.936 & 0.739 & $P<0.001$ \\
\hline & Wet temperature & 0.872 & 0.688 & $P<0.001$ \\
\hline & Globe temperature & 0.969 & 0.765 & $P<0.001$ \\
\hline & Wind speed & 0.311 & 0.245 & $P<0.001$ \\
\hline & Total metabolism & 0.611 & 0.482 & $P<0.001$ \\
\hline & Clothing thermal insulation & 0.485 & 0.383 & $P<0.001$ \\
\hline & Thermal strain & 0.789 & - & $P<0.001$ \\
\hline
\end{tabular}

the linear regression curve between tympanic temperature and PHSRA index. As a result, this index justifies $77 \%$ of the tympanic temperature $\left(\mathrm{R}^{2}=0.77\right)$.

\section{Discussion}

The results showed that extensive ranges of values with normal distributions were collected. Therefore, the novel index extracted from these data is usable for the risk assessment of people with different body characterization in a variety of climatic conditions. In the model of the present study, the variables were divided into two groups, including main and personal factors. The results determined that the main factors with a total coefficient of 0.79 and personal factors with 0.14 had significant direct effects on the tympanic temperature. The results also indicated that the influence of the main factors in producing thermal strain compared to that of personal factors was significantly higher. The findings of other studies support these results. In a study performed by Golbabaei et al. [30], the impact coefficients of the task, environment, and worker variables on the thermal strain were calculated as $0.526,0.279$, and 0.195 , respectively. In the study of Zheng et al. [31], the weights of the task, environment, and worker variables were obtained as $0.540,0.297$, and 0.163 , respectively. These findings are consistent with those of the present study. However, as a result, personal factors make individual differences in susceptibility to heat disorders and illnesses and possess importance in thermal risk assessments. Alfano et al. [32] concluded that a two-dimensional environmental index such as humidex underestimated the body's physiological response under warm conditions. The results of a study conducted by Potter et al. [33] showed that the use of a mathematical model developed by variables of the environment, activity, and clothing was restricted to general predictions of thermal strain and did not provide individual estimations obtained from physiological sensor data. Hence, the use of personal factors in the development of heat stress indices can make accurate predictions of the thermal strain.

The indirect effect coefficients of the personal factors including the body mass index, body surface, maximum aerobic capacity, and age were obtained as $0.145,0.106,-0.064$, and 0.031 , respectively. Brode et al. [34] also studied the effect of individual variables on the thermal comfort evaluated by the universal thermal climate index (UTCI). The results

Table 4 Goodness-of-fit indices of the analyzed model

\begin{tabular}{llll}
\hline Index & Name & Threshold of Fitness & Obtained value \\
\hline Absolute fitness indices & Goodness-of-fit index (GFI) & $>0.9$ & 0.967 \\
& Adjusted goodness-of-fit index (AGFI) & $>0.9$ & 0.920 \\
Comparative fitness indices & Normed fit index (NFI) & $>0.9$ & 0.971 \\
& Comparative fit index (CFI) & $>0.9$ & 0.991 \\
& Incremental fit index (IFI) & $0-1$ & 0.991 \\
Normed fit index & Root mean squared error of approximation (RMSEA) & $<0.1$ & 0.046 \\
& Normed chi-square (CMIN/DF) & $1-3$ & 1.425 \\
P value & & $>0.05$ & 0.071 \\
\hline
\end{tabular}




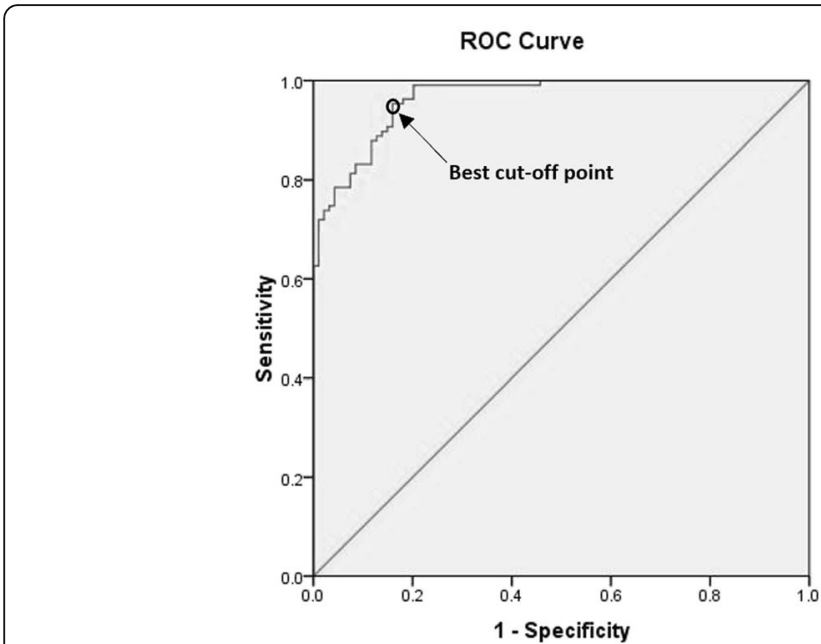

(a)

ROC Curve

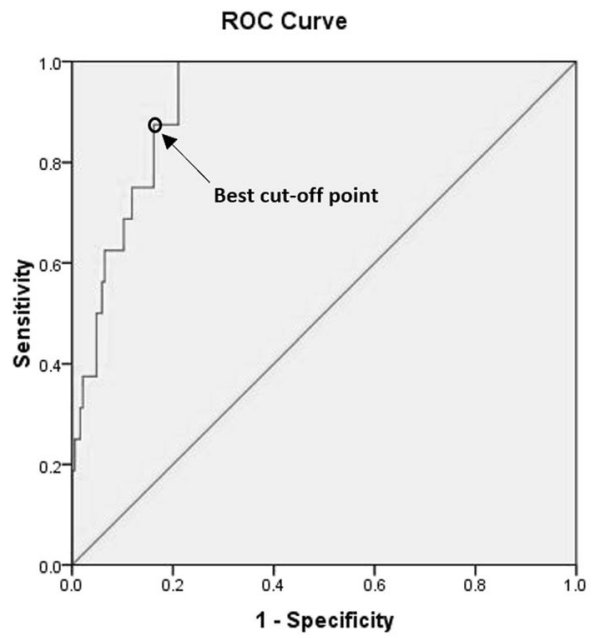

(c)

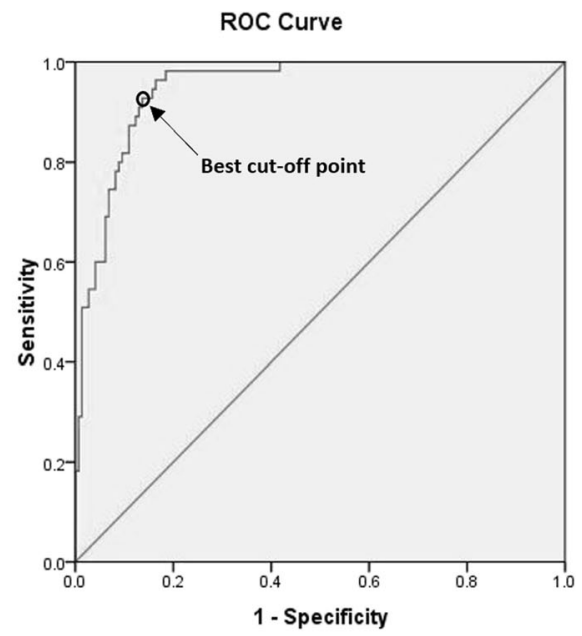

(b)

Fig. 2 Receiver operating characteristic (ROC) curves of (a) low and moderate, (b) moderate and high, and (c) high and very high risk zones

indicated that gender and age had a negligible influence on prediction error, whereas there was an increase in the error for obese people. In a review study performed by Kenny et al. [9], the odds ratio of heat-related death and or hospital admission at obese persons was calculated as 1.2. These results indicate the importance of obesity in assessing thermal risk. Additionally, body surface area plays an essential role in the regulation of tympanic temperature. However, its effect depends on the air temperature. Large body surface area increases the heat absorption in warm and hot environments while it decreases the thermal strain in cool environments. Of personal factors, VO2max had a reverse relationship with the tympanic temperature. These findings are in agreement with those of Havenith and Middendrop [35], who concluded a significant negative correlation between
VO2max with heart rate and core temperature under various climatic conditions. Based on the results, the lowest effect coefficient was related to the variable of age. The results of other studies have been demonstrated that human physical characteristics such as aerobic capacity, body surface area, and fat percentage adjust the influence of age on the thermal strain. Wright et al. [36] concluded that different age groups had similar hydration, thermal, and cardiovascular response when they were matched in terms of demographic characteristics. It may be a reason for the obtained result in the current study. Moreover, the results showed that the environmental variables could impress on VO2max. Craig and Cummings [37] also observed that dehydration due to the activity under thermal conditions decreases the aerobic capacity (VO2max). 


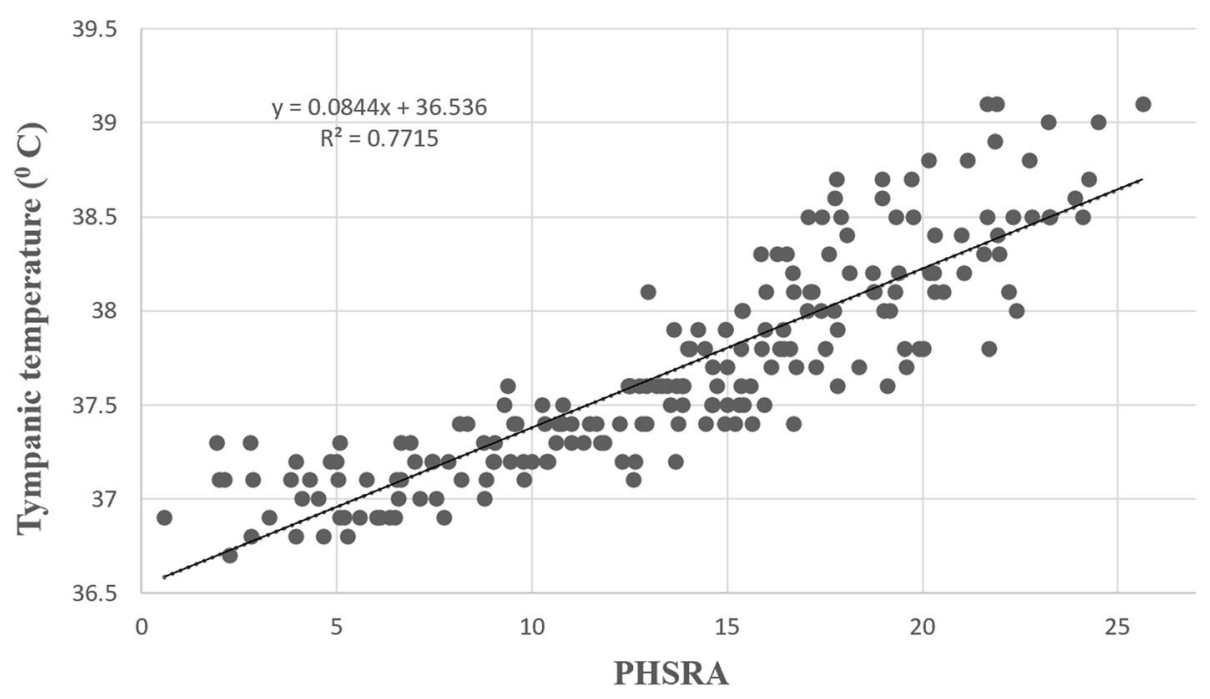

Fig. 3 Linear regression curve between PHSRA index and core temperature

Of the main factors, the highest indirect effects were related to environmental variables, including globe temperature with a coefficient of 0.765 , dry temperature with 0.739 , and wet temperature with 0.688 . The same results were obtained in the study of Dehghan et al. [38]. However, the coefficients of these variables in wet bulb globe temperature (WBGT) index are equal to 0.20 , $0.10,0.70$, respectively [39]. These differences may be due to the use of normalized values in the PHSRA index and the use of non-normalized values in the WBGT index. Based on the results, the wind speed had the lowest impact coefficient among the main factors. This parameter was often unstable during measurements, which diminished its impact on the thermal strain.

Linear regression analysis was used to examine the validity of the novel index. The results showed that the PHSRA index could justify $77 \%$ of the tympanic temperature. In the study of Falahati et al. [40], this value for the WBGT index was equal to $57 \%$. Malchaire [41] concluded that the PHS index predicted $66 \%$ of variations in the rectal temperature. The results of Monazzam et al. [42] study also showed that WBGT and PHS indices justified 71 and $76 \%$ of the aural temperature, respectively. These findings demonstrate that the PHSRA index has an appropriate validity for predicting the thermal strain. This validity may be due to the use of personal and main factors simultaneously in developing the index. As well as, the results showed that the presented model had good fitness, and the diagnostic accuracies of ROC curves were acceptable. A limitation of the present study was the general assessment of all environments by an index. Additionally, it was not possible to apply very accurate equipment such as rectal temperature because of ethical problems.

\section{Conclusion}

In total, the present study showed that personal characteristics in addition to main agents, including environment, metabolism, and clothing, play an important role in producing thermal strain. Therefore, the developed index can be applied to screen and assess people with various personal properties for employing in a variety of thermal conditions. This index can predict the risk of thermal strain and prevent the occurrence of heatrelated illnesses. The results indicated that the developed index had an acceptable validity in the prediction of thermal strain. However, it is suggested that this index is validated in various workplaces with thermal conditions. Its validity can also be investigated to use in non-work environments. Moreover, it is needed that a heat risk assessment index for women is separately developed in future researches.

\section{Abbreviations}

WBGT: Wet bulb global temperature; PHS: Predicted heat strain;

UTCI: Universal thermal climate index; PHSRA: Personal heat strain risk assessment; BMI: Body mass index; VO2max: Maximum aerobic capacity; BSA: Body surface area; SEM: Structural equation modeling; ROC: Receiver operator curves

\section{Acknowledgments}

Not applicable.

\section{Authors' contributions}

SY collected the data and contributed to the manuscript. FG designed the study and wrote the manuscript. MRM and HD were involved in the interpretation of the data, and the coordinator researcher. ARF carried out the statistical analyses of the data. All authors read and approved the final manuscript.

\section{Funding}

This study, as a Ph.D. thesis, has been supported by Tehran University of Medical Sciences \& Health Services grant number 9421138003 . The funding body has played no role in the design of the study, collection of data, 
analysis of data, and interpreting results or in writing the manuscript or in decision to submit the manuscript for publication. The content of this publication is only the responsibility of the authors.

\section{Availability of data and materials}

All data generated and analyzed during this step of study are included in this published article.

\section{Ethics approval and consent to participate}

The protocol was reviewed and approved by the Medical Ethics Committee of Tehran University of Medical Sciences (IR.TUMS.SPH.REC.1397.321). All steps of the study were in accordance with the ethical standards. All participants were asked to fill out the consent form developed by the medical ethics committee, and written informed consent was obtained from all of them.

\section{Consent for publication}

Not applicable.

\section{Competing interests}

The authors declare that they have no conflict of interest.

\section{Author details}

'Department of Occupational Health Engineering, School of Public Health, Tehran University of Medical Sciences, Tehran, Iran. ${ }^{2}$ Department of Occupational Health Engineering, School of Public Health, Isfahan University of Medical Sciences, Isfahan, Iran. ${ }^{3}$ Department of Epidemiology and Biostatistics, School of Public Health, Tehran University of Medical Sciences, Tehran, Iran

Received: 26 December 2019 Accepted: 7 May 2020

Published online: 03 June 2020

\section{References}

1. Luber G, Mcgeehin M. Climate change and extreme heat events. Am J Prev Med. 2008;35(5):429-35.

2. Boeckmann M, Rohn I. Is planned adaptation to heat reducing heat-related mortality and illness? A systematic review. BMC Public Health. 2014;14(1): 1112-25.

3. Venugopal V, Chinnadurai J, Lucas R, Kjellstrom T. Occupational heat stress profiles in selected workplaces in India. Int J Environ Res Public Health 2016:13(1):89-102

4. Ramsey JD, Burford CL, Beshir MY, Jensen RC. Effects of workplace therma conditions on safe work behavior. J Saf Res. 1983;14(3):105-14.

5. Kjellstrom T, Briggs D, Freyberg C, Lemke B, Otto M, Hyatt O. Heat, human performance, and occupational health: a key issue for the assessment of global climate change impacts. Annu Rev Public Health. 2016;37:97-112.

6. Tawatsupa B, Lim LY, Kjellstrom T, Seubsman SA, Sleigh A. Thai cohort study team c. the association between overall health, psychological distress, and occupational heat stress among a large national cohort of 40,913 Thai workers. Glob Health Action. 2010:3(1):5034-44.

7. Leon LR, Bouchama A. Heat stroke. Compr Physiol. 2011;5(2):611-47.

8. Kjellstrom T, Holmer I, Lemke B. Workplace heat stress, health and productivity-an increasing challenge for low and middle-income countries during climate change. Glob Health Action. 2009;2(1):2047-53.

9. Kenny GP, Yardley J, Brown C, Sigal RJ, Jay O. Heat stress in older individuals and patients with common chronic diseases. CMAJ. 2010;182(10):1053-60.

10. Yazdanirad S, Dehghan H, Rahimi Y, Zeinodini M, Shakeriyan M. The relationship between overweight and heart rate in hot and very hot weather under controlled conditions. Health Scope. 2015;4(4):45-50.

11. Hansen A, Bi P, Nitschke M, Pisaniello D, Newbury J, Kitson A. Older persons and heat-susceptibility: the role of health promotion in a changing climate. Health Promot J Austr. 2011;22(4):17-20.

12. Merry T, Ainslie P, Cotter J. Effects of aerobic fitness on hypohydrationinduced physiological strain and exercise impairment. Acta Physiol. 2010; 198(2):179-90.

13. Del Coso J, Hamouti N, Ortega JF, Fernández Elías VE, Mora RR. Relevance of individual characteristics for thermoregulation during exercise in a hot-dry environment. Eur J Appl Physiol. 2011;111(9):2173-81.
14. Havenith G, Coenen JM, Kistemaker L, Kenney WL. Relevance of individual characteristics for human heat stress response is dependent on exercise intensity and climate type. Eur J Appl Physiol. 1998;77(3):231-41.

15. Lu S, Peng H, Gao P. A body characteristic index to evaluate the level of risk of heat strain for a group of workers with a test. Int J Occup Saf Ergon. 2014;20(4):647-59.

16. Glass K, Tait P, Hanna E, Dear K. Estimating risks of heat strain by age and sex: a population-level simulation model. Int J Environ Res Public Health 2015;12(5):5241-55.

17. Hulley S, Cummings S, Browner W, Grady D, Newman T. Designing clinical research: an epidemiologic approach. 4th ed. Philadelphia, PA: Lippincott Williams \& Wilkins; 2013. p. 78-9.

18. ISO 9886: Ergonomics-Evaluation of thermal strain by physiological measurements second edition. Int Org Standard Geneva Switzerland; 2004

19. ISO BS 7243: Ergonomics of the thermal environment-assessment of heat stress using the wbgt (wet bulb globe temperature) index. Int Org Standard Geneva Switzerland; 2017.

20. ISO 7726: Ergonomics of the thermal environment-instruments for measuring physical quantities. Int Org Standard Geneva Switzerland; 1998.

21. ISO 8996: Ergonomics of the thermal environment-Determination of metabolic rate. Int Org Standard Geneva Switzerland; 2004

22. ISO 9920: Ergonomics of the thermal environment-Estimation of thermal insulation and water vapor resistance of a clothing ensemble. Int Org Standard Geneva Switzerland; 2009.

23. Tomlinson DJ, Erskine RM, Morse Cl, Onambélé GL. Body fat percentage, body mass index, fat mass index and the ageing bone: their singular and combined roles linked to physical activity and diet. Nutrients. 2019;11(1): 195-218.

24. Uth N, Sørensen $H$, Overgaard K, Pedersen PK. Estimation of $\dot{V} O 2$ max from the ratio between HR max and HR rest-the heart rate ratio method. Eur J Appl Physiol. 2004;91(1):111-5.

25. $\mathrm{Yu} \mathrm{C}-\mathrm{Y}$, Lin $\mathrm{C}-\mathrm{H}$, Yang $\mathrm{Y}-\mathrm{H}$. Human body surface area database and estimation formula. Burns. 2010;36(5):616-29.

26. Morán-Navarro R, Courel-Ibáñez J, Martínez-Cava A, Conesa-Ros E, SánchezPay A, Mora-Rodriguez R, et al. Validity of skin, oral and tympanic temperatures during exercise in the heat: effects of wind and sweat. Ann Biomed Eng. 2019;47(1):317-31.

27. Amos structural equation modeling. Internet link: https://www.ibm.com/usen/marketplace/structural-equation-modeling-sem.

28. SPSS. Statistics. Internet link. https://www.ibm.com/products/spss-statistics.

29. Gallagher M, Robertson RJ, Goss FL, Nagle-Stilley EF, Schafer MA, Suyama J, et al. Development of a perceptual hyperthermia index to evaluate heat strain during treadmill exercise. Eur J Appl Physiol. 2012;112(6):2025-34.

30. Golbabaei F, Omidvar M, Nirumand F. Risk assessment of heat stress using the AHP and TOPSIS methods in fuzzy environment-a case study in a foundry shop. Health Saf Work. 2019;8(4):397-408.

31. Zheng G, Zhu N, Tian Z, Chen Y, Sun B. Application of a trapezoidal fuzzy AHP method for work safety evaluation and early warning rating of hot and humid environments. Saf Sci. 2012;50(2):228-39.

32. Alfano FR, Palella Bl, Riccio G. Thermal environment assessment reliability using temperature-humidity indices. Ind Health. 2011:49(1):95-106.

33. Potter AW, Blanchard LA, Friedl KE, Cadarette BS, Hoyt RW. Mathematical prediction of core body temperature from environment, activity, and clothing: the heat strain decision aid (HSDA). J Therm Biol. 2017;64:78-85.

34. Bröde $\mathrm{P}$, Krüger EL, Rossi FA, Fiala D. Predicting urban outdoor thermal comfort by the universal thermal climate index UTCl—a case study in southern Brazil. Int J Biometeorol. 2012;56(3):471-80.

35. Havenith $G$, van Middendorp $H$. The relative influence of physical fitness, acclimatization state, anthropometric measures and gender on individual reactions to heat stress. Eur J Appl Physiol Occup Physiol. 1990;61(5-6):419-27.

36. Wright HE, Larose J, Mclellan TM, Hardcastle SG, Boulay P, Kenny GP. Moderate-intensity intermittent work in the heat results in similar low-level dehydration in young and older males. J Occup Environ Hyg. 2014;11(3) 144-53.

37. Craig E, Cummings E. Dehydration and muscular work. J Appl Physiol. 1966; 21(2):670-4

38. Dehghan H, Mortzavi SB, Jafari MJ, Maracy MR. Development and validation of a questionnaire for preliminary assessment of heat stress at workplace. J Res Health Sci. 2015;15(3):175-81.

39. Budd GM. Wet-bulb globe temperature (WBGT) - its history and its limitations. J Sports Sci Med. 2008;11(1):20-32. 
40. Falahati M, Alimohammadi I, Farshad A, Zokaii M, Sardar A. Evaluating the reliability of WBGT and P4SR by comparison to core body temperature. Iran Occup Health. 2012;9(3):22-31.

41. Malchaire J. Occupational heat stress assessment by the predicted heat strain model. Ind Health. 2006;44(3):380-7.

42. Monazzam M, Golbabaei F, Hematjo R, Hosseini M, Nassiri P, Fahang DS.

Evaluation of DI, WBGT, and SWreq/PHS heat stress indices for estimating the heat load on the employees of a petrochemical industry. Int I Occup Hyg. 2014;6(1):6-10.

\section{Publisher's Note}

Springer Nature remains neutral with regard to jurisdictional claims in published maps and institutional affiliations.

Ready to submit your research? Choose BMC and benefit from:

- fast, convenient online submission

- thorough peer review by experienced researchers in your field

- rapid publication on acceptance

- support for research data, including large and complex data types

- gold Open Access which fosters wider collaboration and increased citations

- maximum visibility for your research: over $100 \mathrm{M}$ website views per year

At BMC, research is always in progress.

Learn more biomedcentral.com/submissions 